\title{
New Insights into the Molecular Mechanisms of Selected Anticancer Metal Compounds through Bioinformatic Analysis of Proteomic Data
} \author{
Alessandra Modesti ${ }^{1 *}$ \\ ${ }^{1}$ Department of Clinical and Preclinical Biomedical Sciences, University of Florence, Italy \\ ${ }^{2}$ Laboratory of Functional Proteomics, Molecular Biology Department, University of Siena, Italy \\ ${ }^{3}$ Department of Chemistry, University of Florence, Italy \\ ${ }^{4}$ Department of Chemistry and Industrial Chemistry, University of Pisa, Italy \\ ${ }^{5}$ Department of Experimental and Clinical Medicine, University of Florence, Italy \\ \#These two authors equally contributed to this work
}

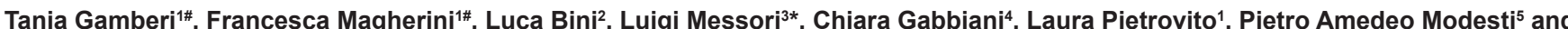

\begin{abstract}
Research has increasingly focused on cytotoxic gold and ruthenium compounds as anticancer drug candidates. From proteomic investigations, clearly emerged that a few different cellular pathways relevant for the comprehension of the pharmacological actions are specifically modulated by them. To gain a better intepretation of their cellular effects, we decided to undertake a comprehensive bioinformatic analysis of the available proteomic results. Data obtained from prevously published treatments were grouped and mapped in the PPI Spider on the web portal Bioprofiling (http://www.BioProfiling.de/gene_list). A preliminary map of protein-protein interactions was built up, and some mechanistically relevant features highlighted. In total, 34 proteins resulted to be direct gold and ruthenium compounds interactors; we built a statistically significant interaction network that grouped together all the proteins differentially expressed. Moreover, we showed as intermediate protein cREL a Component of the NF-kappa-B. This study explores the affected protein pathways from an interactomic prospective stressing the importance of advanced bioinformatic analysis.
\end{abstract}

Keywords: Proteomics of metallodrugs; Protein-protein interaction; Bioinformatic analysis

\section{Introduction}

Proteomic profiling offers the opportunity to identify proteins that mediate apoptotic pathways, when cells are treated with cytotoxic agents [1]. Proteomic results have the potential to provide new insight into the molecular mechanisms of this group of molecules at the cellular level [2]. More than $99 \%$ of currently approved clinical drugs are organic compounds. In contrast, the percentage of metal-containing drugs (metallodrugs) is very low [3]. In cancer chemotherapy, however, platinum coordination compounds are essential agents, with proven efficacy against a variety of tumors. The discovery of the anticancer properties of cisplatin (cis-dichloro diammineplatinum (II), cis$\left[\mathrm{Pt}^{\mathrm{II}} \mathrm{Cl}_{2}\left(\mathrm{NH}_{3}\right)_{2}\right]$ has triggered the development of several other metalbased compounds [4]. Because of the established clinical applications of these platinum-based drugs, the number of research initiatives to identify other metallodrugs that can be used in cancer therapy has increased. The use of transition metal compounds other than platinum has also attracted attention, to improve the therapeutic effects and to overcome the disadvantages of current platinum-based drugs [5]. Various metal complexes (e.g., $\mathrm{Pt}, \mathrm{Au}$, and $\mathrm{Ru}$ ) are currently evaluated, either clinically or experimentally, as therapeutic agents in treatment of malignant diseases, including several cancer types.

Gold coordination complexes, for instance, demonstrate outstanding cytotoxic properties, and certain ruthenium complexes possess a remarkable ability to inhibit metastases of solid invasive tumors. Previous studies showed that cytotoxic gold(III) compounds are able to induce cell death through apoptosis [6,7]; essentially triggered through a direct mitochondrial damage [8]. Within this frame, the pivotal role of thioredoxin reductase as a probable target for cytotoxic gold compounds was highlighted [9]. Among currently investigated anticancer metallodrugs, a few ruthenium- compounds hold great promise as experimental antimetastatic agents [10,11]. Interestingly, their relevant antimetastatic actions are usually associated to weak cytotoxicity, and to acceptable profiles of systemic toxicity that render them very suitable for further drug development and for clinical use [12]. For instance, imidazolium trans-[tetrachloro(DMSO)(imidazole) ruthenate(III)] NAMI-A was found to reduce dramatically the number and the size of metastases in certain in vivo models of cancer, e.g. the Lewis lung carcinoma, and is currently undergoing phase II clinical trials [13]. Similarly, the ruthenium(II) organometallic complex [Ru(n6-toluene)Cl2(PTA)] (where PTA=1,3,5-triaza-7-phosphatricyclo-[3.3.1.1] decane) named RAPTA-T is weakly cytotoxic in vitro, while showing favorable antimetastatic effects in vivo [14], as well as remarkable anti-angiogenic properties [15]. The mode of action of antimetastatic ruthenium compounds remains elusive and largely unexplored. For these reasons, a proteomic approach was utilized for investigating the mode of action of these anticancer metallodrugs $[16,17]$.

In previous papers, we reported lists of proteins found to be differentially expressed in the human ovarian cancer cisplatin-sensitive

*Corresponding authors: Alessandra Modesti, Department of Clinical and Preclinical Biomedical Sciences, University of Florence, Viale Morgagni 50, 50134 Firenze, Italy, Tel: +390554598311; Fax: +390554598905; E-mail: alessandra modesti@unifi.it

Luigi Messori, Department of Chemistry, University of Florence, Via della Lastruccia, 3-13, 50019 Sesto Fiorentino, Firenze Italy, Tel: +390554573388; Fax +390554573385; E-mail: luigi.messori@unifi.it

Received May 08, 2013; Accepted June 10, 2013; Published June 12, 2013

Citation: Gamberi T, Magherini F, Bini L, Messori L, Gabbiani C, et al. (2013) New Insights into the Molecular Mechanisms of Selected Anticancer Metal Compounds through Bioinformatic Analysis of Proteomic Data. J Proteomics Bioinform S6: 006 doi:10.4172/jpb.S6-006

Copyright: (c) 2013 Gamberi T, et al. This is an open-access article distributed under the terms of the Creative Commons Attribution License, which permits unrestricted use, distribution, and reproduction in any medium, provided the original author and source are credited. 
cell line (A2780/S), after treatment with four different cytotoxic gold compounds, namely: Auranofin [2], Auoxo6 [2], AuL12 [1] and Au2Phen [1]. In a very recent paper, we have used for the first time, 2D-DIGE to investigate the mode of action of two anticancer ruthenium compounds, namely NAMI-A and RAPTA-T in A2780/S human cancer cells [18]. Changes in the expression of intracellular proteins after the treatment at non-cytotoxic concentrations were monitored.

In this paper, we carry out a detailed bioinformatic analysis on proteins identified in those previous proteomic studies, including the protein-protein interaction network, in order to better understand the biological processes involved in metallodrugs treatment, and find possible common features in the mechanism of action of these compounds. To interpret all the protein lists obtained in our previous proteomics results, with the two classes of metallodrugs, we used a BioProfiling.de [19] tool: PPI spider [20] freely available on the analytical web portal (http://www.BioProfiling.de/gene_list). In one submission, the protein/gene list can be analyzed by a collection of tools. The input list is translated into a network model, according to the topology of the two web-based tools. We provide models of protein interactions that represent the most probable scenario of how proteins identified within the list are connected, in order to identify a possible combination of metallodrugs in experimental chemotherapy of cancer disease, to increase the effectiveness of metallodrugs treatment. The expression of many of these proteins resulted affected by most of the gold compounds used, and this strengthens the validity of the results.

\section{Methods}

\section{Bioinformatic analysis}

BioProfiling.de: BioProfiling.de provides a comprehensive analytical toolkit for the interpretation of protein lists. Asinput, BioProfiling.de accepts a protein list. As output, in one submission, the gene list is analyzed by a collection of tools, which employs advanced enrichment or network-based statistical frameworks. BioProfiling.de provides a common interface for the collection of recently developed tools [19]; description and details of the tools can be found in original publications [20]. The gene list is profiled with respect to the most information available regarding gene function, protein interactions, pathway relationships, in silico predicted microRNA to gene associations, as well as, information collected by text mining. The web portal is freely available at http://www.BioProfiling.de/gene_list.

To better understand the key regulated biological processes occurring after metallodrugs A2780/S cells treatment, bioinformatics analysis to the differentially expressed list of proteins identified by our previous quantitative proteomic studies, were carried out. The network analysis used has been freely available web-based tool for the interpretation of experimentally derived protein lists in the context of a global PPI network. A dataset containing the standard gene symbols of the identified proteins was uploaded. The significantly enriched PPI networks have been determined with the default parameter settings.

Statistical methodology: PPI Spider implements a statistical framework for the interpretation of protein lists in the context of a global PPI network. The statistical significance of the inferred model is estimated based on the distribution of the model size for a random protein list. Statistical significance of the model is computed by a Monte Carlo simulation procedure [19,20].

Network visualization using Cytoscape: Cytoscape (http:// www.cytoscape.org/) is a software platform for visualizing molecular interaction networks and integrating these interactions with gene expression profiles. Cytoscape supports several algorithms for the layout of networks [21].

\section{Results}

\section{Bioinformatic analysis of proteomic data}

To gain a deeper insight into the mechanism of action of selected anticancer Gold and Ruthenium compounds, and establish whether these metallodrugs have common protein targets, we performed a bio-informatic analysis on the lists of proteins previously identified by proteomic studies. We have used the web-based tool BioProfiling. de, which provides a common interface for the collection of recently developed tools; description and details of the tools can be found in the original publications [20].

We used proteins previously identified, showing variation in expression level following treatment with AuL12, Au2Phen, Auoxo6, Auranofin and with NAMI-A and RAPTA-T in a cisplatin-sensitive human ovarian cancer cell line (A2780/S).

To start the analysis, we uploaded a text file with the 34 proteins, and we selected Homo sapiens as organism. We put in the same analysis all the proteins, listed in Table 1, whose expression resulted modified after the two different treatments. The expression of many of these proteins resulted affected by most of the gold compounds used, and this strengthens the validity of the results. The table reported in Figure 1 summarizes the results for this submission using the PPI Spider. In the table, it is also shown the models' definition, which specifies the maximal allowed distance between two input proteins connected (D0 means directly connected, D1 one intermediate is allowed, D2 two intermediate are allowed), the number of input proteins covered by the system, and the corresponding significance of the best inferred model. As it is evident the inferred network model D2 covers 22 proteins of the 34 used as input. The p-value estimated for this model is statistically significant (p-value less than 0.005). We decided to analyze this network, and in Figure 1 is reported, a graphical illustration of the protein-protein interaction network created by PPI Spider and obtained by Cytoscape: http://www.cytoscape.org/, the software platform for visualizing the results. Four proteins belong to the Ruthenium molecules treatments (circle in the Figure 1), and 18 proteins to the Gold metallodrugs. This network includes intermediate proteins not previously detected in our proteomic studies, reported in Table 2, and represented as triangles in the network of Figure 1. These intermediate proteins could be potentially interesting targets for metallodrugs, even if their expression level could not be directly influenced by the treatment.

Among them, the software found few proteins correlated with antiproliferation, and/or apoptosis. To group the proteins present in the PPI network, we divided them in two classes: Class A including proteins involved in apoptosis, cellular proliferation and DNA stability, and Class B that includes proteins responsible of cytoskeleton dynamics, splicing regulation and protein biosynthesis.

\section{The two classes are reported in Figure 1:}

a) Class A-Apoptosis, cellular proliferation and DNA stability: Important nodes of this Group are represented by two intermediate proteins: the TNF receptor-associated factor 1 (TRAF1-Q13077), an adapter molecule that plays a role in the regulation of cell survival and 
Citation: Gamberi T, Magherini F, Bini L, Messori L, Gabbiani C, et al. (2013) New Insights into the Molecular Mechanisms of Selected Anticancer Metal Compounds through Bioinformatic Analysis of Proteomic Data. J Proteomics Bioinform S6: 006. doi:10.4172/jpb.S6-006

Page 3 of 6

\begin{tabular}{|c|c|c|c|c|}
\hline $\begin{array}{c}\text { Accession } \\
\text { number }\end{array}$ & Protein name & Top Function & Gold & Ruthenium \\
\hline $\mathrm{P} 07437$ & Tubulin beta chain & constituent of microtubules. & Guidi et al. [1] & \\
\hline Q9BWD1 & Acetyl-CoA acetyltransferase, cytosolic & 2 acetyl-CoA = CoA + acetoacetyl-CoA. & & Guidi et al. [18] \\
\hline P60174 & Triosephosphate isomerase & $\begin{array}{l}\text { associated with cardiomyopathy and increased } \\
\text { susceptibility to infection. }\end{array}$ & Magherini et al. [2] & \\
\hline P55209 & Nucleosome assembly protein 1-like 1 & chromatin formation and regulation of proliferation. & Guidi et al. [1] & \\
\hline P29692 & Elongation factor 1-delta & Protein synthesis & & Guidi et al. [18] \\
\hline P23919 & Thymidylate kinase & Pyrimidine metabolism & Guidi et al. [1] & Guidi et al. [18] \\
\hline P49773 & Histidine triad nucleotide-binding prot 1 & $\begin{array}{l}\text { Hydrolyzes adenosine } 5 \text { '-monophosphoramidate } \\
\text { substrates }\end{array}$ & $\begin{array}{c}\text { Guidi et al. [1] } \\
\text { Magherini et al. [2] }\end{array}$ & Guidi et al. [18] \\
\hline Q9Y3F4 & Ser-thr kinase receptor-associated protein & spliceosomal snRNP assembly & Guidi et al. [1] & \\
\hline Q9NQR4 & Omega-amidase NIT2 & omega-amidase activity & Guidi et al. [1] & Guidi et al. [18] \\
\hline P30041 & Peroxiredoxin-6 & redox regulation of the cell. & Magherini et al. [2] & \\
\hline P62253 & Ubiquitin-conjugation enzyme E2 G1 & Protein modification & & Guidi et al. [18] \\
\hline P31943 & Heterog nuclear ribonucleoprot $\mathrm{H}$ & ribonucleoprotein complexes. & Magherini et al. [2] & \\
\hline P09429 & High mobility group protein B1 & $\begin{array}{l}\text { DNA binding proteins that associates with chromatin and } \\
\text { bend DNA. }\end{array}$ & Magherini et al. [2] & \\
\hline Q9NRF9 & DNA pol epsilon sub 3 & nucleosome-remodeling activity & & Guidi et al. [18] \\
\hline P62258 & 14-3-3 protein epsilon & Adapter protein binds to a large number of partners. & Guidi et al. [1] & \\
\hline P63104 & 14-3-3 protein zeta/delta & $\begin{array}{l}\text { Adapter protein implicated in the regulation of signaling } \\
\text { pathways. }\end{array}$ & Guidi et al. [1] & \\
\hline P12004 & $\begin{array}{l}\text { Proliferating cell nuclear antigen } \\
\text { CICLIN }\end{array}$ & $\begin{array}{l}\text { This protein is an auxiliary protein of DNA polymerase } \\
\text { delta }\end{array}$ & Guidi et al. [1] & \\
\hline P07339 & Cathepsin D & active in intracellular protein breakdown. & & Guidi et al. [18] \\
\hline P62937 & $\begin{array}{l}\text { Peptidyl-prolyl cis-trans isomerase A } \\
\text { Cyclophilin A }\end{array}$ & accelerate the folding of proteins. & Guidi et al. [1] & \\
\hline P61978 & Heterog nuclear ribonucleoprot $\mathrm{K}$ & pre-mRNA-binding proteins. & Guidi et al. [1] & \\
\hline P15311 & EZRINA & connections of major cytoskeletal structures. & Magherini et al. [2] & \\
\hline Q06830 & Peroxiredoxin 1 & redox regulation of the cell & Magherini et al. [2] & Guidi et al. [18] \\
\hline Q9UMX0 & Ubiquilin 1 & Interacts with the proteasome $19 S$ subunit & Guidi et al. [1] & \\
\hline P14174 & Macrophage migration inhibitory factor & Pro-inflammatory cytokine & Guidi et al. [1] & \\
\hline P60709 & Actin, cytoplasmic 1 & involved in various types of cell motility. & Guidi et al. [1] & \\
\hline Q14257 & Reticulocalbin-2 & Binds calcium. & Guidi et al. [1] & \\
\hline P24534 & Elongation factor 1-beta & Protein synthesis & Guidi et al. [1] & \\
\hline P61758 & Prefoldin subunit 3 & Binds specifically to cytosolic chaperonin & & Guidi et al. [18] \\
\hline P26447 & Protein S100-A4 & calcium-binding protein & & Guidi et al. [18] \\
\hline P28838 & Cytosol aminopeptidase & $\begin{array}{l}\text { involved in the processing turnover of intracellular } \\
\text { proteins }\end{array}$ & Guidi et al. [1] & \\
\hline Q99714 & 3-hydroxyacyl-CoA dehydrogenase type-2 & Functions in mitochondrial tRNA maturation. & Magherini et al. [2] & \\
\hline P33316 & $\begin{array}{l}\text { Deoxiuridine } 5 \text { ' triphosphate } \\
\text { nucleotidohydrolase, mit }\end{array}$ & involved in nucleotide metabolism & & Guidi et al. [18] \\
\hline Q969Q6 & Serine/Treonine-protein phosphatase $2 \mathrm{~A}$ & play a role in the activation-induced cell death & & Guidi et al. [18] \\
\hline Q08752 & Peptidyl-prolyl cis-trans isomerase D & accelerates the folding of proteins & & Guidi et al. [18] \\
\hline
\end{tabular}

Table 1: Experimentally identified proteins list used as input in PPI Spider analysis. 


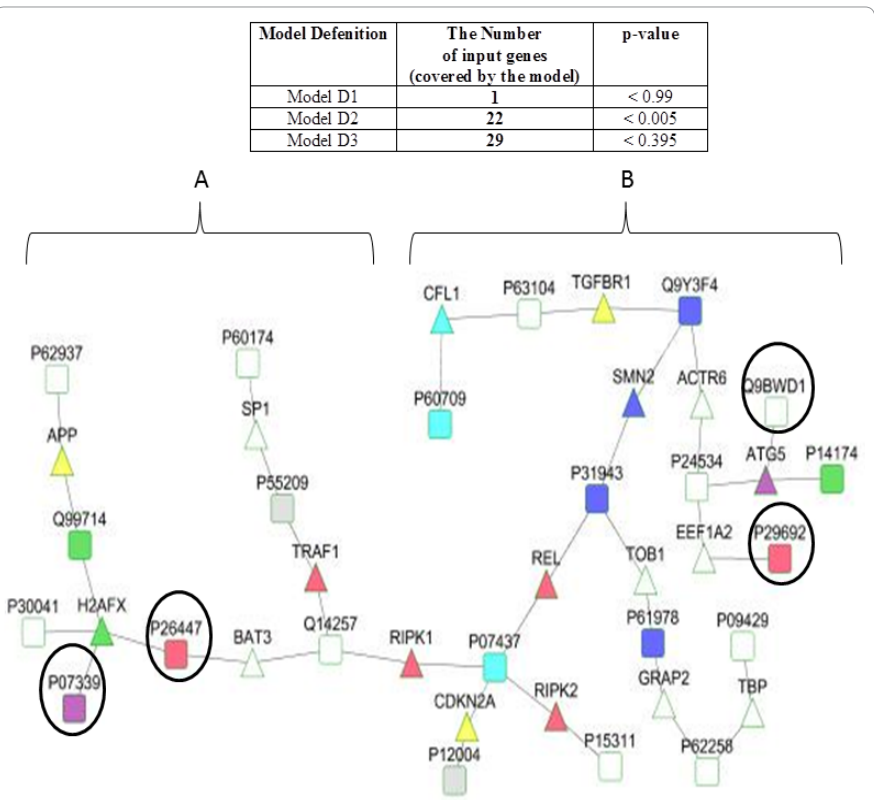

Figure 1: (Upper side) Table of results obtained by PPI Spider analysis after the submission of the previously identified proteins list and (lower side) network inference model D2 visualization obtained by Cytoscape. See text for details.

apoptosis [22], and the Transcription factor Sp1 (SP1-P08047). This protein can activate or repress transcription in response to physiological and pathological stimuli, and regulates the expression of a large number of genes involved in apoptosis, differentiation and immune responses [23]; moreover, it plays a role in the cellular response to DNA damage. Among the proteins of Class A, we found the previously identified Reticulocalbin-2 (Q14257) [1], belonging to the CREC protein family, including promising biomarkers in a variety of diseases [24]. We found other proteins strictly correlated with the DNA damage and DNA assembly, and identified in previous proteomics experiments. Among them, the apoptotic marker NALP1 (Nucleosome assembly protein 1 P55209) [1], connected with the two previously discussed intermediate nodes: the adapter molecule TRAF1 and the transcription factor Sp1. An intermediate node mapped in this network and involved in DNA repair mechanisms [25] is the variant histone H2A (H2AFX-P16104), which replaces conventional $\mathrm{H} 2 \mathrm{~A}$ histon in a subset of nucleosomes [26].

b) Class B-Cytoskeleton dynamics, splicing regulation and protein biosynthesis: In this class are included many proteins present as intermediate nodes and involved in cytoskeleton organization, like the protein Cofilin1 (CFL-P23528), important for the regulation of actin cytoskeleton dynamics, and for the progression through mitosis [27]. It is connected to the cytoplasmic $\beta$ actin (P60709), identified by proteomics experiments [1], that is a component of the cytoskeleton and a mediator of internal cell motility. Among this group, we found another intermediate node, an actin-related protein involved in cytoskeleton organization [28] (ACTR6-Q9GZN1). The protein SMN2 (Q16637) is a node between two input proteins involved in splicing: the Heterogeneous nuclear ribonucleoprotein H (P31943) [2], and the Serine-threonine kinase receptor-associated protein (Q9Y3F4) [1]. The SMN2 protein plays an essential role in spliceosomal assembly, and is required for pre-mRNA splicing [29]. Moreover, an intermediate node which connects the two elongation factors, previously identified by proteome analysis (Elongation factor 1-beta - P24534 [1] and Elongation factor 1-delta - P29692 [18], is the Elongation factor 1-alpha
2 (EEF1A2-Q05639). These components of the eEF1 complex have the canonical functions in translation elongation [30], and many noncanonical functions, including roles in nuclear export events, turnover of misfolded proteins, binding and bundling of the actin cytoskeleton and apoptosis. Moreover, the cellular senescence has been found associated with changes of eEF1 levels in colon and lung cancer cell lines [31]. The A and B classes of proteins are connected together by an intermediate node: Receptor-like protein kinase1 (RIPK1-Q13546) a Serine-threonine kinase, which transduces inflammatory and celldeath signals (necroptosis) and DNA damage [32].

\section{Enriched network analysis}

The new list of proteins, obtained by the PPI Spider analysis described above, and including: the proteins previously identified by proteomics experiments and reported in Table 1, and the nodes corresponding to new intermediate proteins and inferred by the PPI spider analysis, has been used as input list for an enriched second PPI analysis. This new list of proteins was used, in order to identify a new network model to provide new insight into possible biological mechanisms of metallodrugs. The table of Figure 2 shows the results obtained with this new submission: the inferred network model D1 covers 40 proteins from the 52 used as input, and with the model D2 are covered 42 proteins. Both the models show a statistical significance with a $\mathrm{p}<0.005$. Since the proteins connected in the model D1 belong to the input list, and there are not missing proteins in this model, we decided to analyze the model D2 to find new information about new intermediate proteins (nodes), correlated with the input list. In Figure 2 is represented the graphical illustration of the D2 model obtained by Cytoscape, and modified by the authors. In this sub-network are present two intermediate proteins (triangles in the Figure 2): the Glyceraldehyde-3-phosphate dehydrogenase (GAPDH-P04406), and the Cleavage stimulation factor subunit 2 (CSTF2-P33240). In our network, we found GAPDH connected with the Peroxiredoxin-1 (Q 06830) [2,18], identified by previous proteomic analysis, which is involved in redox regulation of the cell. Recently, Maller et al. [33], found that GAPDH's oxidation state controls the protein biosynthesis, and its nitrosylation state is important to induce apoptosis. Moreover,

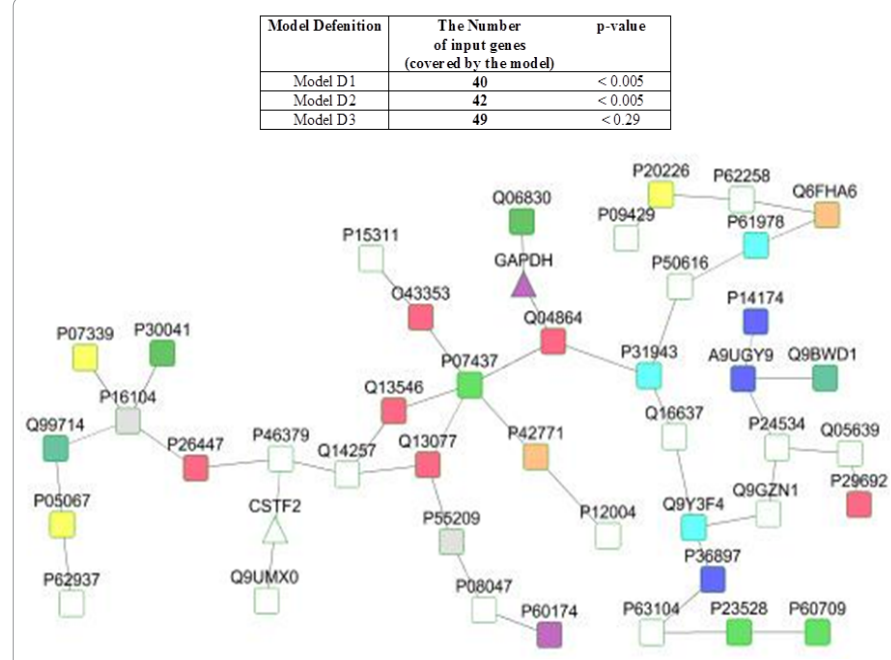

Figure 2: (Upper side) Table of results of the network obtained by PPI Spider analysis after the submission of the enriched proteins list and (lower side) network inference model D2 visualization obtained by Cytoscape. See text for details. 
Citation: Gamberi T, Magherini F, Bini L, Messori L, Gabbiani C, et al. (2013) New Insights into the Molecular Mechanisms of Selected Anticancer Metal Compounds through Bioinformatic Analysis of Proteomic Data. J Proteomics Bioinform S6: 006. doi:10.4172/jpb.S6-006

Page 5 of 6

\begin{tabular}{|c|c|c|}
\hline Entry name & ID & Top Function \\
\hline SP1-human & P08047 & Transcription factor Sp1 \\
\hline TRAF1_human & Q13077 & TNF receptor-associated factor 1 \\
\hline BAT3 - BAG6_HUMAN & P46379 & Large proline-rich protein BAG6 \\
\hline H2AFX & P16104 & Histone H2A.x \\
\hline APP & P05067 & Amyloid beta A4 protein \\
\hline RIPK1 & Q13546 & Receptor-interacting serine/threonine-protein kinase 1 (EC 2.7.11.1) \\
\hline CDKN2A & Q9NXV6 & CDKN2A-interacting protein (Collaborator of ARF) \\
\hline RIPK2 & O43353 & Receptor-interacting serine/threonine-protein kinase 2 (EC 2.7.11.1) \\
\hline REL & Q04864 & Component of the NF-kappa-B p65-c-Rel complex \\
\hline TOB1 & P50616 & Protein Tob1 \\
\hline GRAP2 & Q6FHA6 & GRAP2-related adaptor protein 2 \\
\hline TBP & $\mathrm{P} 17980$ & $26 S$ protease regulatory subunit $6 \mathrm{~A}$ \\
\hline SMN2 & Q16637 & Survival motor neuron protein \\
\hline TGFBR1 & P36897 & TGF-beta receptor type-1 (TGFR-1) (EC 2.7.11.30) \\
\hline CFL & P23528 & Cofilin-1 regulation of cell morphology and cytoskeletal organization \\
\hline ACTR6 & Q9GZN1 & Actin-related protein 6 (hArp6) (Harpx) \\
\hline ATG5 & A9UGY9 & ATG5 autophagy related 5 homolog (S. cerevisiae), isoform CRA_b (ATG5 autophagy related 5-like) \\
\hline EEF1A2 & Q05639 & Elongation factor 1-alpha 2 (EF-1-alpha-2) (Eukaryotic elongation factor $1 \mathrm{~A}-2)(\mathrm{eEF} 1 \mathrm{~A}-2)$ (Statin-S1) \\
\hline
\end{tabular}

Table 2: Intermediate nodes inferred by PPI network.

they propose its potential peroxidase activity and the decomposition of $\mathrm{H}_{2} \mathrm{O}_{2}$ by GAPDH is already acknowledged. In this network, GAPDH is also connected with REL (Q04864) component of the NF-kappa-B p65-c-Rel complex, which plays a role in the regulation of apoptosis [34]. CSTF2 is one of the multiple factors required for polyadenylation and 3'-end cleavage of mammalian pre-mRNAs. This subunit is directly involved in the binding to pre-mRNAs. Aragaki et al. [35], found that there is a significant correlation of CSTF2 expression, with poor prognosis for patients with lung cancers. CSTF2 could play important roles in cell proliferation and invasion.

\section{Discussion}

The goal of this work was to elucidate whether the list of proteins previously identified by proteomics analysis, could perform biological interactions. Many biological functions are carried out by the integrated activity of interacting proteins. We aimed to build a single, representative network that possibly grouped together all the proteins differentially expressed, and reported in all previously published papers from our laboratory. It is hypothesized that proteins interact through specific interactions and a web tool, which employs a network-based statistical framework for the interpretation of protein lists has been used in this work. We used the global PPI Spider network, using all the previously identified proteins as input. In order to reduce the probability of false positives, most of the proteins used as input, have been previously validated by western blot analyses. Moreover, the expression of many of these proteins resulted affected by most of the gold compounds used, and this strengthens the validity of the results. After this first analysis, we obtained a new list of proteins, including the intermediate nodes, new proteins representing common interactors, as predicted by PPI Spider. We reload this "enriched" new list for a further PPI analysis. Comparing all the results, we noticed that the functions of some proteins could be correlated. The first correlation is between two proteins that are involved in RNA processing. The second correlation we found was between two proteins involved in connections of cytoskeletal components to membrane: the protein Ubiquilin-1 and the protein Ezrin. In our recent paper, we reported that two ruthenium compounds caused proteomic alterations, and we found that 9 proteins are in common between RAPTA-T and NAMI-A, implying that their respective mechanisms are highly correlated [18]. Analysis of all these proteins by PPI Spider resulted a significant network model, indicating two classes of proteins correlated to each other and belonging to: i) Apoptosis, cellular proliferation and DNA stability, and ii) Cytoskeleton dynamics, splicing regulation and protein biosynthesis. Among these two groups, we found some intermediate proteins able to connect most of the proteins in the input list. A new protein-protein interaction analysis, using the enriched new input list resulted in a second network model, showing as intermediate nodes two proteins involved in cellular redox regulation and dynamics RNA stability, suggesting a common mechanism of action for the metallodrugs studied. These proteins may be further investigated as possible drug targets, and more extensive bioinformatics analyses will be carried out to better identify and characterize the cellular perturbations induced by these substances.

\section{Acknowledgements}

We thank AIRC IG 12085 for financial support.

\section{References}

1. Guidi F, Puglia M, Gabbiani C, Landini I, Gamberi T, et al. (2012) 2D-DIGE analysis of ovarian cancer cell responses to cytotoxic gold compounds. Mol Biosyst 8: 985-993.

2. Magherini F, Modesti A, Bini L, Puglia M, Landini I, et al. (2010) Exploring the biochemical mechanisms of cytotoxic gold compounds: a proteomic study. $J$ Biol Inorg Chem 15: 573-582.

3. Gaynor D, Griffith DM (2012) The prevalence of metal-based drugs as therapeutic or diagnostic agents: Beyond platinum. Dalton Trans 41: 1323913257.

4. Nagy EM, Ronconi L, Nardon C, Fregona D (2012) Noble metal-dithiocarbamates precious allies in the fight against cancer. Mini Rev Med Chem 12: 1216-1229. 
Citation: Gamberi T, Magherini F, Bini L, Messori L, Gabbiani C, et al. (2013) New Insights into the Molecular Mechanisms of Selected Anticancer Metal Compounds through Bioinformatic Analysis of Proteomic Data. J Proteomics Bioinform S6: 006. doi:10.4172/jpb.S6-006

5. Kouodom MN, Ronconi L, Celegato M, Nardon C, Marchiò L, et al. (2012) Toward the selective delivery of chemotherapeutics into tumor cells by targeting peptide transporters: tailored gold-based anticancer peptidomimetics. J Med Chem 55: 2212-2226.

6. Wang Y, He QY, Sun RW, Che CM, Chiu JF (2005) GoldIII porphyrin 1a induced apoptosis by mitochondrial death pathways related to reactive oxygen species. Cancer Res 65: 11553-11564.

7. Bindoli A, Rigobellob MP, Scutarib G, Gabbianic C, Casinid A, et al. (2009) Thioredoxin reductase: A target for gold compounds acting as potential anticancer drugs. Coord Chem Rev 253: 1692-1707.

8. Rigobello MP, Scutari G, Boscolo R, Bindoli A (2002) Induction of mitochondrial permeability transition by auranofin, a gold(I)-phosphine derivative. $\mathrm{Br} \mathrm{J}$ Pharmacol 136: 1162-1168.

9. Liu JJ, Liu Q, Wei HL, Yi J, Zhao HS, et al. (2011) Inhibition of thioredoxin reductase by auranofin induces apoptosis in adriamycin-resistant human K562 chronic myeloid leukemia cells. Pharmazie 66: 440-444.

10. Komeda S, Casini A (2012) Next-generation anticancer metallodrugs. Curr Top Med Chem 12: 219-235.

11. Nagy EM, Pettenuzzo A, Boscutti G, Marchiò L, Dalla Via L, et al. (2012) Ruthenium(II/III)-based compounds with encouraging antiproliferative activity against non-small-cell lung cancer. Chemistry 18: 14464-14472.

12. Alessio E, Mestroni G, Bergamo A, Sava G (2004) Ruthenium antimetastatic agents. Curr Top Med Chem 4: 1525-1535.

13. Bergamo A, Gava B, Alessio E, Mestroni G, Serli B, et al. (2002) Rutheniumbased NAMI-A type complexes with in vivo selective metastasis reduction and in vitro invasion inhibition unrelated to cell cytotoxicity. Int J Oncol 21: 13311338.

14. Bergamo A, Masi A, Dyson PJ, Sava G (2008) Modulation of the metastatic progression of breast cancer with an organometallic ruthenium compound. Int J Oncol 33: 1281-1289.

15. Nowak-Sliwinska $P$, van Beijnum JR, Casini $A$, Nazarov AA, Wagnieres $G$, et al. (2011) Organometallic ruthenium(II) arene compounds with antiangiogenic activity. J Med Chem 54: 3895-3902.

16. Guidi F, Landini I, Puglia M, Magherini F, Gabbiani C, et al. (2012) Proteomic analysis of ovarian cancer cell responses to cytotoxic gold compounds. Metallomics 4: 307-314.

17. Gabbiani C, Magherini F, Modesti A, Messori L (2010) Proteomic and metallomic strategies for understanding the mode of action of anticancer metallodrugs. Anticancer Agents Med Chem 10: 324-337.

18. Guidi F, Modesti A, Landini I, Nobili S, Mini E, et al. (2013) The molecular mechanisms of antimetastatic ruthenium compounds explored through DIGE proteomics. J Inorg Biochem 118: 94-99.

19. Antonov AV (2011) BioProfiling.de: analytical web portal for high-throughput cell biology. Nucleic Acids Res 39: W323-W327.

20. Antonov AV, Dietmann S, Rodchenkov I, Mewes HW (2009) PPI spider: a tool for the interpretation of proteomics data in the context of protein-protein interaction networks. Proteomics 9: 2740-2749.

21. Masoudi-Nejad A, Ansariola M, Kashani ZR, Salehzadeh-Yazdi A Khakabimamaghani S (2012) CytoKavosh: a cytoscape plug-in for finding network motifs in large biological networks. PLoS One 7: e43287.

22. Honoré B (2009) The rapidly expanding CREC protein family: members, localization, function, and role in disease. Bioessays 31: 262-277.

23. Rajandram R, Bennett NC, Wang Z, Perry-Keene J, Vesey DA, et al. (2012) Patient samples of renal cell carcinoma show reduced expression of TRAF1

Citation: Gamberi T, Magherini F, Bini L, Messori L, Gabbiani C, et al. (2013) New Insights into the Molecular Mechanisms of Selected Anticancer Metal Compounds through Bioinformatic Analysis of Proteomic Data. J Proteomics Bioinform S6: 006. doi:10.4172/jpb.S6-006

This article was originally published in a special issue, Microarray

Proteomics handled by Editor(s). Dr. Qiangwei Xia, University of WisconsinMadison, USA compared with normal kidney and functional studies in vitro indicate TRAF1 promotes apoptosis: potential for targeted therapy. Pathology 44: 453-459.

24. Chuang JY, Wang SA, Yang WB, Yang HC, Hung CY, et al. (2012) Sp1 phosphorylation by cyclin-dependent kinase 1/cyclin B1 represses its DNAbinding activity during mitosis in cancer cells. Oncogene 31: 4946-4959.

25. Paull TT, Rogakou EP, Yamazaki V, Kirchgessner CU, Gellert M, et al. (2000) A critical role for histone $\mathrm{H} 2 \mathrm{AX}$ in recruitment of repair factors to nuclear foci after DNA damage. Curr Biol 10: 886-895.

26. van Attikum H, Gasser SM (2009) Crosstalk between histone modification during the DNA damage response. Trends Cell Biol 19: 207-217.

27. Wang WS, Zhong HJ, Xiao DW, Huang X, Liao LD, et al. (2010) The expression of CFL1 and N-WASP in esophageal squamous cell carcinoma and its correlation with clinicopathological features. Dis Esophagus 23: 512-521.

28. Klose T, Abiatari I, Samkharadze T, De Oliveira T, Jäger C, et al. (2012) The actin binding protein destrin is associated with growth and perineural invasion of pancreatic cancer. Pancreatology 12: 350-357.

29. Bebee TW, Dominguez CE, Chandler DS (2012) Mouse models of SMA: Tools for disease characterization and therapeutic development. Hum Genet 131 1277-1293.

30. Sasikumar AN, Perez WB, Kinzy TG (2012) The many roles of the eukaryotic elongation factor 1 complex. Wiley Interdiscip Rev RNA 3: 543-555.

31. Byun HO, Han NK, Lee HJ, Kim KB, Ko YG, et al. (2009) Cathepsin D and eukaryotic translation elongation factor 1 as promising markers of cellular senescence. Cancer Res 69: 4638-4647.

32. Dunai ZA, Imre G, Barna G, Korcsmaros T, Petak I, et al. (2012) Staurosporine induces necroptotic cell death under caspase-compromised conditions in U937 cells. PLoS One 7: e41945.

33. Maller C, Schröder E, Eaton P (2011) Glyceraldehyde 3-phosphate dehydrogenase is unlikely to mediate hydrogen peroxide signaling: studies with a novel anti-dimedone sulfenic acid antibody. Antioxid Redox Signal 14: 49-60.

34. Winterbourn CC (2008) Reconciling the chemistry and biology of reactive oxygen species. Nat Chem Biol 4: 278-286.

35. Aragaki M, Takahashi K, Akiyama H, Tsuchiya E, Kondo S, et al. (2011) Characterization of a cleavage stimulation factor, 3' pre-RNA, subunit 2, 64 $\mathrm{kDa}$ (CSTF2) as a therapeutic target for lung cancer. Clin Cancer Res 17 5889-5900.

Submit your next manuscript and get advantages of OMICS Group submissions

Unique features:

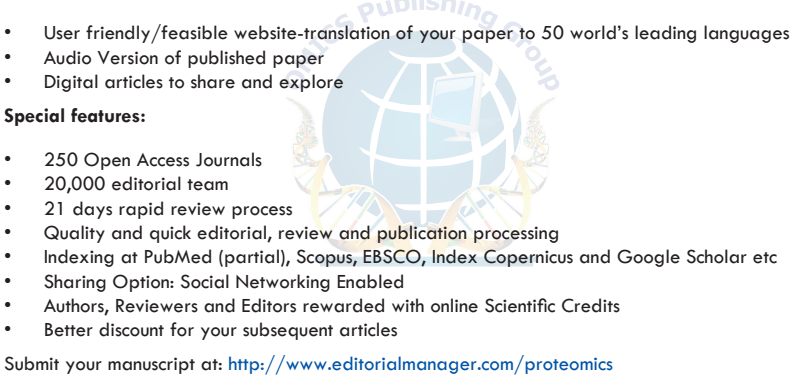

